\title{
Asentamientos Yauyos en el valle alto del río Cañete: distritos Huangáscar y Víñac
}

\author{
Consuelo González Madueño* \\ Carmen Pacheco Sivirichi**
}

Resumen El presente trabajo es el resultado de un reconocimiento arqueológico llevado a cabo en los distritos de Huangáscar y Viñac, ubicados en la cuenca alta del río Cañete. El texto comienza con una introducción y localización de la zona de estudio, así como una presentación de los antecedentes acerca del grupo étnico de los yauyos. Posteriormente, se presentan los resultados del reconocimiento, incluyendo información sobre la arquitectura y la cerámica de los sitios de Huantanga, Viñaccancha, Huamani, Quencho y Pucahuasi. Finalmente, se presenta un análisis de los asentamientos investigados, seguido de una discusión sobre los datos arqueológicos en relación con la información etnohistórica relacionada con los yauyos.

Palabras clave Sierra de Lima, grupo yauyos, etnohistoria, análisis de asentamientos, Período Intermedio Tardío, cerámica.

Abstract This paper is the result of an archeological survey that was conducted in the districts
of Huangáscar y Viñac, located in the high basin of the Cañete river. The text starts
with an introduction and definition of the studied area, as well as a summary of the
previous research on the Yauyos ethnic group. Then, the results of the survey are
presented, including data on architecture and ceramics of the sites of Huantanga,
Viñaccancha, Huamani, Quencho, and Pucahuasi. Finally, an analysis of the men-
tioned settlements is presented, followed by a discussion about the relation between
the archaeological data and the ethohistorical information about the Yauyos.

Keywords Lima highlands, Yauyos group , ethnohistory, settlement analysis, Late Intermediate Period, ceramics.

* Museo de Arqueología y Antropología de la UNMSM. Correo electrónico: arqueotec@latinmail.com

** Arqueóloga de la UNMSM. Correo electrónico: sivirichi@hotmail.com 


\section{Introducción}

En la provincia de Yauyos desde hace algún tiempo se vienen realizando trabajos arqueológicos, pero éstos aún no se publican. Nuestra intención con el presente artículo es motivar la continuidad en las investigaciones y publicaciones.

Este artículo es el resultado preliminar de los trabajos de reconocimiento arqueológico realizados, durante el año 1997, con la finalidad de entender el funcionamiento e interrelación de cinco sitios ubicados en la margen izquierda del río Huangáscar.

Contamos con muy poca información arqueológica sobre el área, donde destaca el trabajo realizado por arqueólogos sanmarquinos en los años de 1994 y 1997, en los actuales pueblos de Lunahuaná y Yauyos con el propósito de estudiar la ocupación inca (Ruiz y Echevarría 2002).

Sobre el área específica de nuestra investigación tenemos datos de lingüistas como Alfredo Torero, Gerald Taylor y María Ginocchio. Por otro lado, el antropólogo Matos Mar señala que, "la gente de Huangáscar y otros pueblos ubicados en el valle alto del río Cañete han comercializado desde tiempos remotos con los pueblos de Lunahuaná, Pacarán, Zuñiga y San Juan ubicados en el valle medio del río Cañete" (Matos Mar, 1950:8,9). César Fonseca coloca a las comunidades de los distritos de Huangáscar y Vínac en el grupo de comunidades de agricultores y pastores seminómades (Fonseca 1988).

\section{La zona de estudio}

Nuestra área de estudio comprendió los distritos de Huangáscar y de Víñac, ubicados en la margen izquierda del río Huangáscar, cuenca alta del río Cañete, provincia de Yauyos, departamento de Lima(Figura 1).

Las antiguas comunidades de la cuenca del río Cañete ocupaban una vertiente de cada uno de los afluentes del río Cañete y por esto tenían acceso a todos los ambientes ecológicos de sus respectivos valles (Fonseca 1988).

\section{El grupo Yauyos}

La característica marcada de la Sierra Central durante el Período Intermedio Tardío (1000 a 1476 d.C.) fue su regionalismo: coexistían grupos étnicos locales de diferente tamaño y

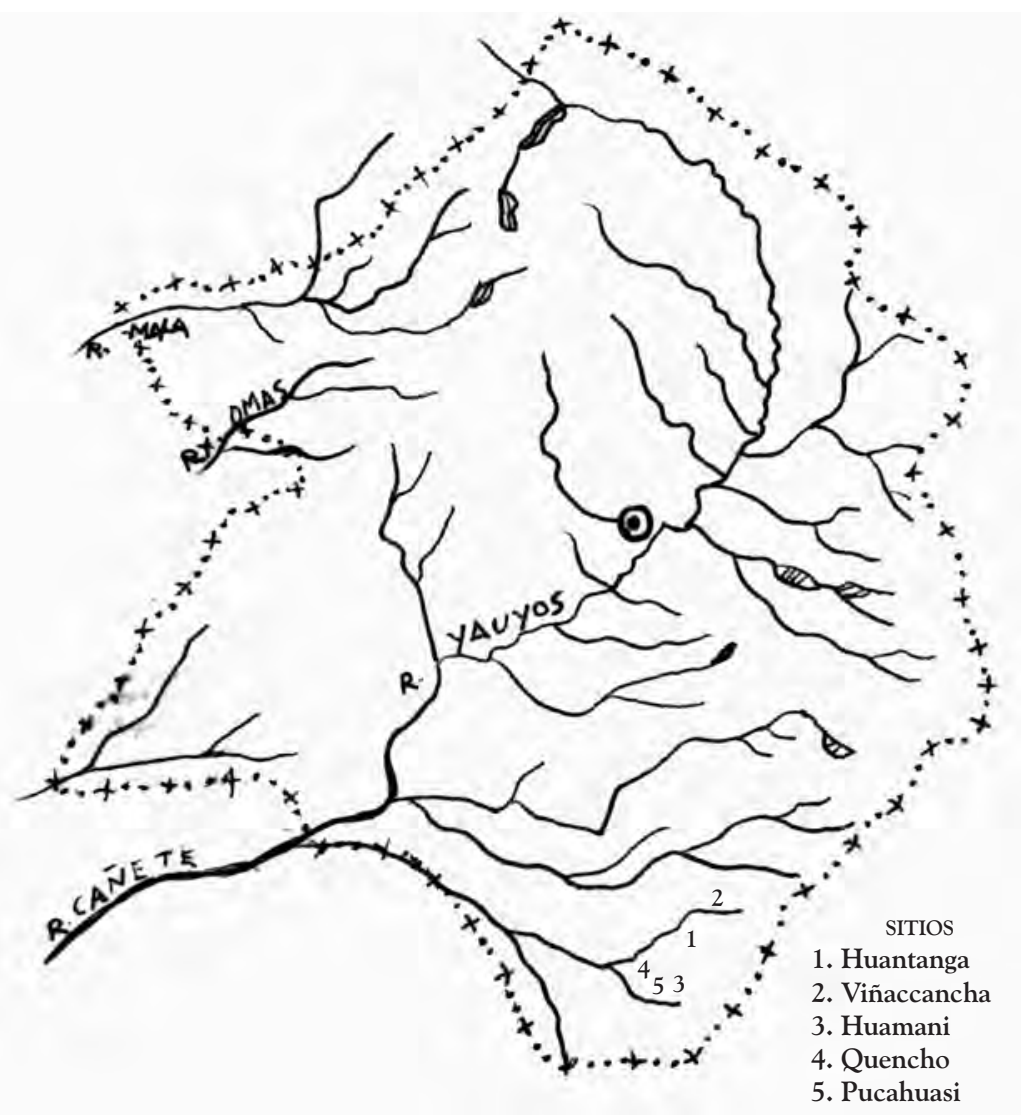

Figura 1. Ubicación de los sitios arqueológicos en la zona de estudio. 
grado de complejidad, cada uno con sus propias peculiaridades arquitectónicas y de cerámica.

Uno de estos grupos fueron los yauyos que se desarrollaron en la sierra de Lima, en las actuales provincias de Yauyos y Huarochirí. Sobre este grupo se tiene dos fuentes principales de información: la Relación de Dávila Briceño y la que recogió Francisco de Ávila sobre Huarochirí.

Los yauyos fueron un pueblo que primero habitó el valle alto del río Cañete y, posteriormente, el crecimiento demográfico los obligó a conquistar nuevos territorios a lo largo de la cordillera andina del actual departamento de Lima (Rostworowski 1989), movilizándose primero hacia la costa del río Cañete, donde los guarcos les opusieron tenaz resistencia, luego avanzaron hacia las cabeceras de los ríos Mala, Chilca, Lurín, Rímac y Chillón, dominando con el tiempo esta región (Rostworowski 1978).
Los límites de los yauyos serían, por el norte, con los atavillos (Canta); por el sur con los chocorvos (Huancavelica); por el oeste con los guarco y los yungas; y por el este con los huancas (de Jauja y Tarma). (Dávila Briceño 1586).

Según la información dada por el corregidor de Huarochirí, Diego Dávila Briceño, en 1586, territorialmente estaban los yauyos divididos en Hanan (actual Yauyos) y Hurin (actual Huarochirí), o sea Alto y Bajo, y comprendían varios señoríos pequeños con la supremacía del señor de Huarochirí sobre los demás (Dávila Briceño 1586:75) (Figura 2).

El repartimiento de Hanan yauyos (actual provincia de Yauyos) comprendió dos encomiendas: Mancos y Laraos; éstas, a su vez, abarcaban 11 pueblos, pero en el mapa elaborado por Dávila Briceño (1586), para la zona sur oeste, solo pone como límite a los chocorvos sin indicar

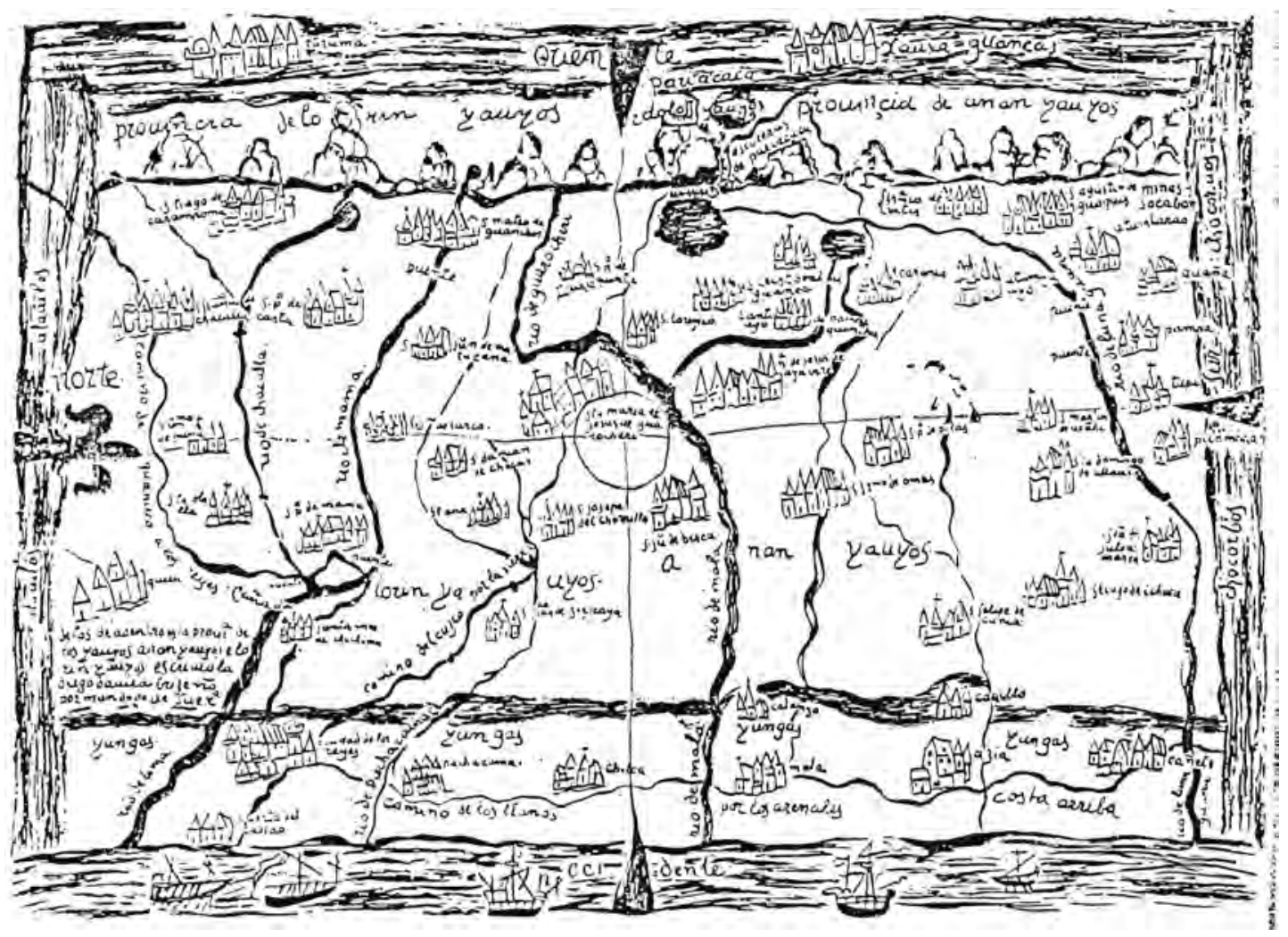

Figura 2. Mapa de Dávila Briceño, 1586. 
que pueblos habitaban estas zonas. Este vacío es llenado con la información contenida en un manuscrito de los jesuitas sobre las "Idolatrías de los indios Huachos (Huancavelica) y Yauyos" (1613). En él se menciona que los pueblos yauyos eran San Pedro Huácra, Santiago de Chupamarca, Víñac, Huangáscar, Chocos, Aco, Apure, Tanai, Ongos Cacha, Chavín y Tsaca; todos ellos aficionados a las idolatrías y que, como los de Huarochirí, adoraban a Pariacaca (Anónimo 1613:183).

Debemos destacar que en las encomiendas otorgadas por Francisco Pizarro se nota una falta de derroteros geográficos. Los españoles procedían a dividir la tierra por pueblos, primando así el concepto de divisiones menores sobre áreas más extensas, esto contribuyó a la creación de fronteras imprecisas, comosucedió con los yauyos.

En los documentos del padre Francisco de Ávila, las conquistas de los yauyos se mezclan con los mitos, relatándose las conquistas del dios Pariacaca, dios de los yauyos, quien victorioso avanza hacia otras tierras y destierra a Huallallo Carhuincho hacia el este (valle del Mantaro) (Ávila, 1598:153-162).

Los mancos y laraos ocuparon la cuenca alta del río Cañete; los laraos en la margen izquierda ocuparon la parte más meridional del territorio de los yauyos, y estarían limitando con los chunku (etnia perteneciente a los huancas) y los astos (etnia perteneciente a los anqara) que se ubicaban al otro lado de la cordillera, en el valle del Mantaroy Huancavelica respectivamente.

Durante la expansión del imperio incaico, los yauyos opusieron fuerte resistencia; posteriormente se aliaron a ellos. Los incas impusieron su idioma, el quechua, pero no los dominaron por mucho tiempo debido a la invasión española. Los yauyos hablaban una lengua muy ligada al aymara que sería el kauki, hablado actualmente en el distrito de Tupe.

\section{Propósito de investigación}

Conocemos que durante el Intermedio Tardío se presentó en la Sierra Central una variedad de grupos multiétnicos que formaron naciones y funcionaron como estados independientes, presentándose conflictos generalizados, como lo demuestran los asentamientos de carácter fortificado (Morales 1993).

Uno de esos grupos fueron los yauyos, de los cuales se tiene mayor información etnohistórica (Dávila 1964; Ávila 1966; Rostworowski 1978,1980,1988); ellos mantenían constantes ataques con sus vecinos costeños al oeste, los chocorbos al sur, los huancas y tarmas al este y los atavillos y canta al norte (Dávila 1964).

Esta evidencia etnohistórica debe estar corroborada por la evidencia arqueológica, pero faltan estudios que indiquen cómo se desenvolvían los yauyos en las cuencas altas del Rímac, Lurín y Cañete; qué tipo de relaciones mantenían con los diferentes grupos asentados en los valles medios y bajos.

Para la cuenca del río Chillón se sostiene que hubo pugnas entre las sociedades costeñas y serranas por tierras en el valle medio apropiadas para el cultivo de coca (Marcus, Silva, 1988; Rostworowski 1978; Dillehay 1987).

En tal sentido, buscamos definir qué tipo de relación se dio en el valle alto de la margen izquierda del río Cañete, donde se ubican varios sitios arqueológicos aún no estudiados. Otro problema es el referido a los límites del tipo territorial que tenían los yauyos por el lado sur. Con respecto a esto tenemos que referirnos a los sitios arqueológicos presentes en el área de estudio, explicar su ubicación y variedad arquitectónica.

\section{Análisis de asentamientos}

En nuestro estudio se realizó el reconocimiento de cinco sitios arqueológicos, se hizo el registro correspondiente y las descripciones respectivas (Figura 1). Los sitios visitados fueron:

\section{Huantanga}

Se ubica a 3,100 m.s.n.m., al sur del pueblo de Vincullay y al sur oeste del pueblo de Vínac. El sitio de Huantanga es de dimensiones peque- 


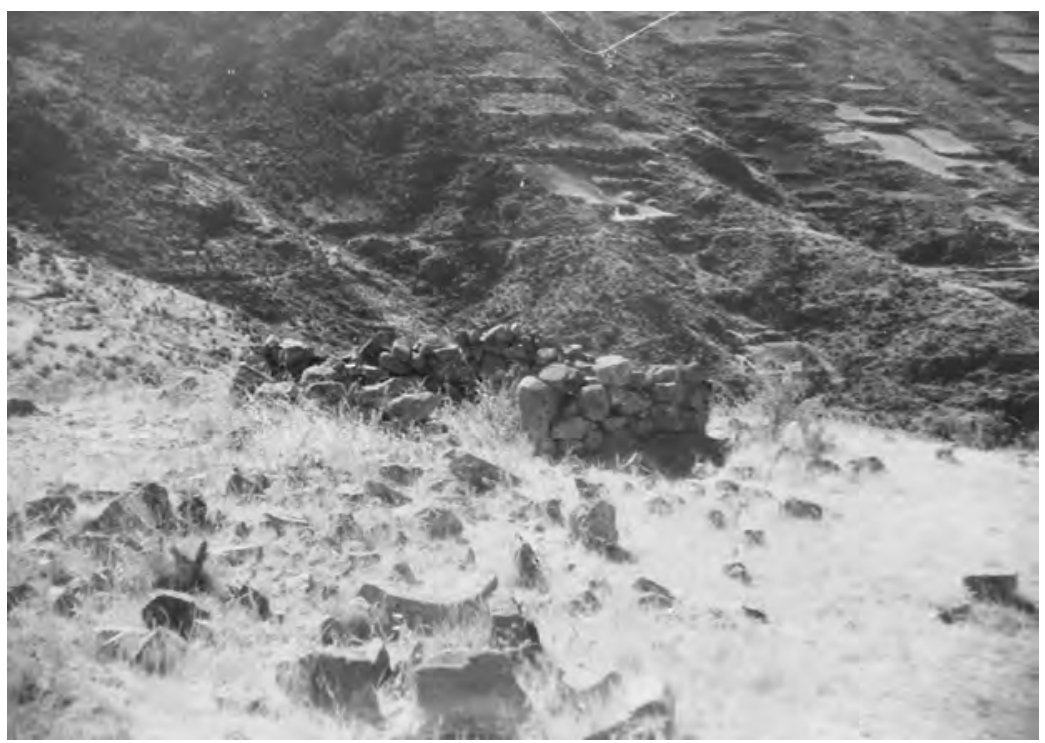

Fotografía 1. Estructura circular, Viñaccancha, Vínac. grafía 1) la mayoría de ellas miden $5 \mathrm{~m}$ de diámetro a proxim ad a mente. Destacan los andenes que bordean las laderas de los cerros.

Todas las estructuras están espaciadas y se emplazan sobre una topografía desnivelada. Se presentan algunas estructuras amorfas por el lado del camino de herradura que baja al pueblo.

Ubicada en la parte más alta se encuentra una plaza casi rectangular de $30 \mathrm{~m}$. En sus extremos este y ñas. Su arquitectura se emplaza sobre una pequeña colina cuyo suelo es compacto. Consiste en tres estructuras semisubterráneas de planta cuadrangular que miden un promedio de $2 \mathrm{~m}$ de largo por $1.5 \mathrm{~m}$ de ancho.

La técnica constructiva consiste en el uso de piedras canteadas unidas con argamasa de barro, que presentan cubiertas compuestas de grandes lajas. Aparentemente, habrían cumplido la función de tumbas por presentar algunos restos óseos en su interior.

\section{Viñaccancha}

Ubicado en el distrito de Víñac. Se halla en el cerro del mismo nombre, a 3,536 m.s.n.m., al noreste del pueblo de Víñac.

El sitio arqueológico se encuentra muy deteriorado ya que sus estructuras han sido reacondicionadas para actividades ganaderas y agrícolas actuales. Los comuneros viñaquinos han parcelado la zona, distinguiéndose los muros que separan las parcelas, los cuales han sido levantados con material proveniente de las estructuras arqueológicas. Registramos estructuras circulares y en algunos casos solo quedan las huellas de la base, sin presencia de muros. Las estructuras más pequeñas miden $2.6 \mathrm{~m}$ de diámetro, (Foto- oeste se ubican grandes rocas a modo de estrado, desde donde se observan los sitios de Pucahuasi, Huamani y Quencho.

Hay presencia de murallas de protección y de acueductos cerca de la plaza. Estos acueductos llevarían agua desde las lagunas de Runtuni y Huarmicocha.

A unos $15 \mathrm{~m}$ de distancia en dirección este de la plaza se encuentra un corral circular que mide $17 \mathrm{~m}$ de diámetro aproximadamente, con un alto máximo de $1 \mathrm{~m}$ del muro que se conserva, y un ancho de la entrada de $60 \mathrm{~cm}$. La técnica constructiva empleada en el sitio de Viñaccancha es el de la piedra canteada unida con argamasa de barro.

\section{Huamani}

Se ubica al sur este del sitio de Pucahuasi, en el distrito de Huangáscar, en la cumbre del cerro del mismo nombre a 3.577 m.s.n.m.

Los pobladores de los caseríos aledaños nos dieron referencias vagas sobre este sitio y rara vez se acercaban a la cima del cerro: "cada pueblo actual reverencia de manera particular un cerro o una cumbre cercana. En él reside Huamaní, el ancestro al que le entregan ofrendas y libaciones cuando se desea asegurar su protección. La mayoría 
de los casos, la residencia del Huamaní es precisamente una ruina prehistórica" (Lavalle 1983).

$\mathrm{El}$ acceso al sitio es dificultoso por el lado noreste por presentar una fuerte pendiente, la cual es menor por el norte, donde se ubican las estructuras arqueológicas de esta zona. Las primeras estructuras que se observan son los restos de una muralla que en algunos tramos fue reconstruida por la gente ya que les servía para separar los senderos del actual camino por donde transitan.

Por el norte nos encontramos con recintos que tienen $5 \mathrm{~m}$ de diámetro aproximadamente, con accesos de $60 \mathrm{~cm}$ de anchoy muros de 30 a 40 $\mathrm{cm}$ de ancho; muchos de estos recintos se encuentran aglutinados y mayormente sus entradas se orientan al Este. Distinguimos en algunos recintos circulares, al interior y pegado al muro, depósitos semi subterráneos de planta semicircular de $1 \mathrm{~m}$ de diámetro aproximadamente. En el área baja encontramos solo un recinto rectangular con un depósito semisubterráneo y circular de $80 \mathrm{~cm}$ de diámetro, adosado a una esquina interna. Este recinto tiene $8 \mathrm{~m}$ de largo por $3 \mathrm{~m}$ de ancho, con el acceso orientado al Oeste. Uno de sus muros forma parte de un muro de contención que da lugar a una plataforma artificial, teniendo unalto de muro máximo de $2.20 \mathrm{~m}$.

A medida que se va ascendiendo se encuentran muros de contención que dividen al sitio en varios niveles, permitiendo la construcción de recintos.

El cerro Huamani se caracteriza por terminar en unas crestas rocosas por lo que a medida que se asciende, el número de recintos se va reduciendo por el poco espacio disponible. La técnica constructiva tiene un mejor acabado y una diferencia marcada con respecto a las estructuras y elementos arquitectónicos encontrados en las partes cercanas a la muralla.

En estas zonas encontramos dos recintos cuadrangulares que presentan esquinas curvas con ventanas de forma cuadrangular de $25 \mathrm{~cm}$ de alto y $25 \mathrm{~cm}$ de ancho (Figura 3). En la parte alta, se ha aprovechado el desnivel del suelo para

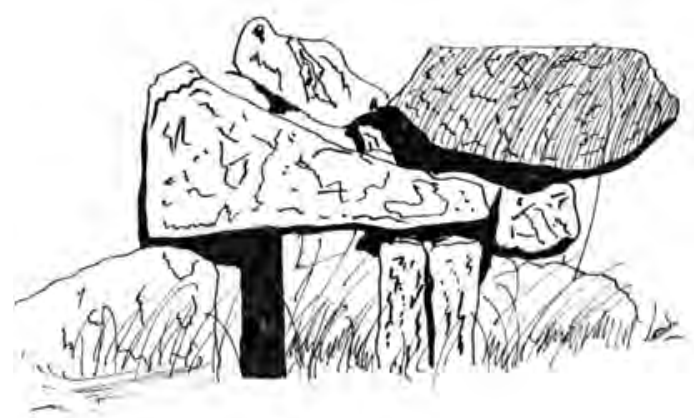

Figura 3. Detalle de la construcción de una ventana en la cara interna del muro, Huamani, Huangáscar.

utilizarlo en la construcción de los muros de los recintos, donde encontramos dos recintos rectangulares, uno de ellos con sus cuatro muros completos y acceso orientado al Este, y con un ancho de $60 \mathrm{~cm}$. Los muros tienen un ancho de $60 \mathrm{~cm}$ y un alto máximo de $2.45 \mathrm{~m}$.

También ubicamos escalinatas que conducen a varios niveles superiores (Fotografía 2). Al

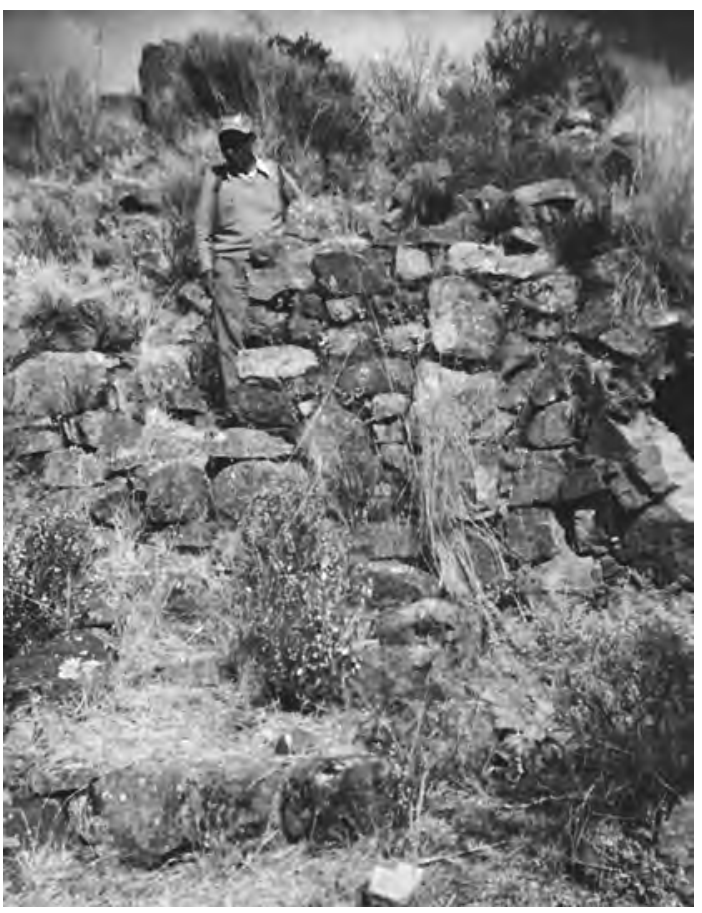

Fotografía 2. Escalinata del sitio Huamani, Huangáscar. 
subir por uno de ellos encontramos otro recinto rectangular con orientación oeste-este; presenta un depósito semisubterráneo adosado al muro. Este recinto se caracteriza por presentar sólo tres muros ya que al buscar el muro oeste no encontramos huellas de que hubiera existido. (Fotografía 3).

Aloeste de este recinto ubicamos la entrada de un recinto rectangular cuyos muros se encuentran caídos. Destaca el muro de acceso por presentar bloques de piedras trabajadas dispuestas horizontalmente y unidas con argamasa de barro (Figura 4).

En este nivel y por el lado sur se distingue una plataforma natural de $3 \mathrm{~m}$ de largo aproximadamente, en la que encontramos cuatro bloques de roca maciza; 2 de ellas parecen haber formado parte de un solo bloque, el cual fue trabajado para formar una especie de entrada orientada al Este, que tal vez pudo tener una función de observatorio astronómico. Desde aquí se tiene una visión estratégica de los cerros aledaños (Fotografía 4).

Al noreste de la plataforma natural hallamos bloques macizos de rocas; bajando a otro nivel

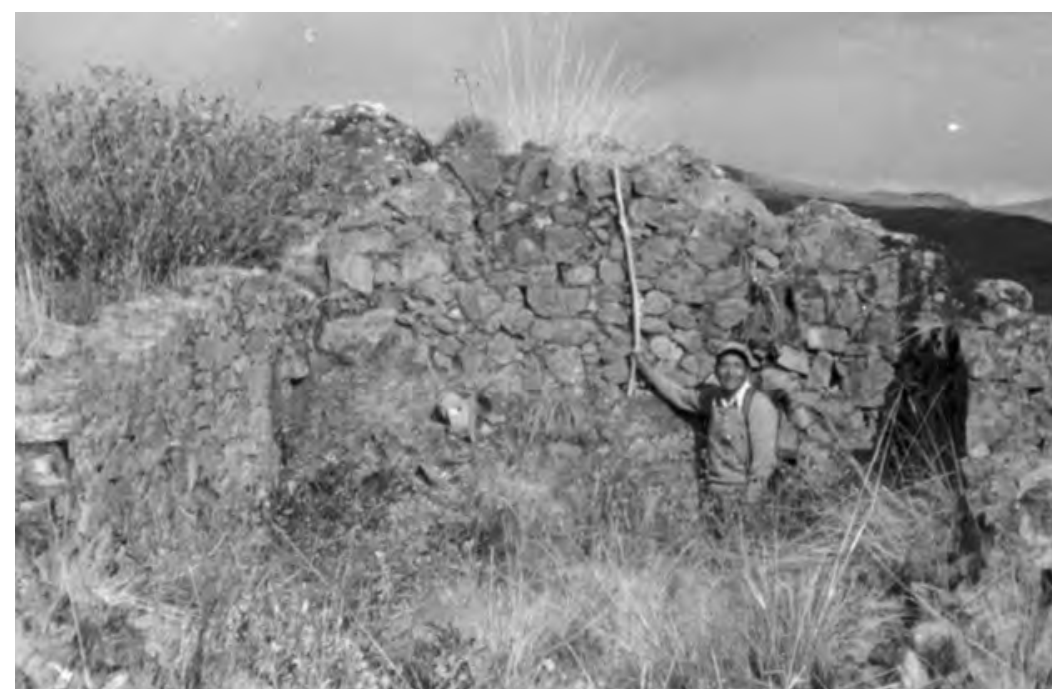

Fotografía 3. Recinto rectangular con tres muros, Huamani, Huangáscar.

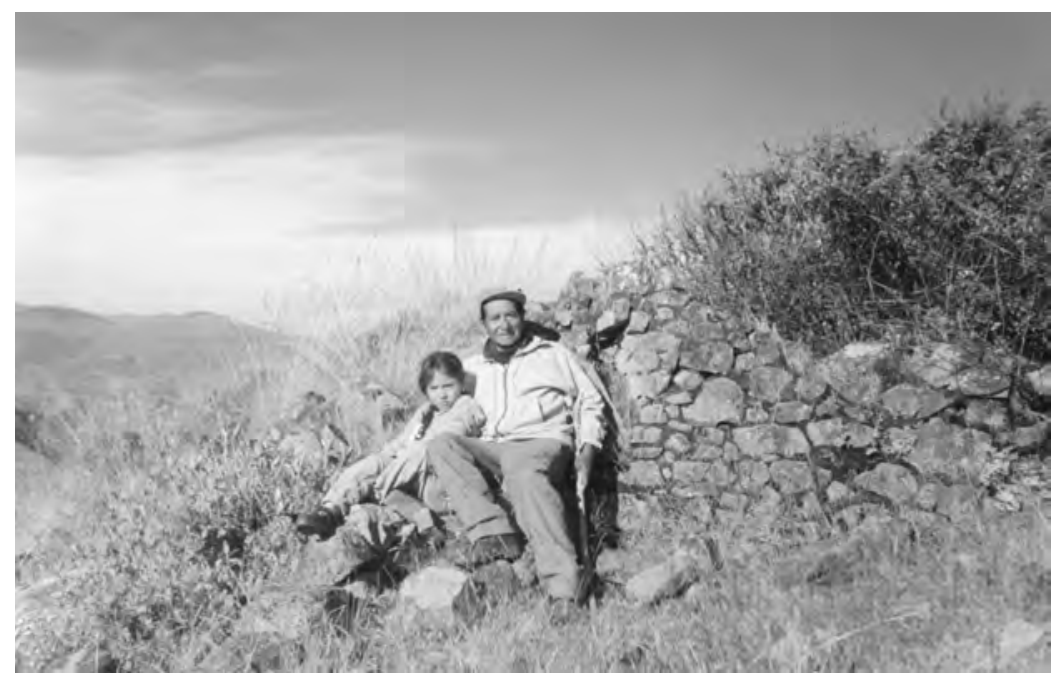

Fotografía 4. Vista de la entrada a Huamani, Huangáscar.

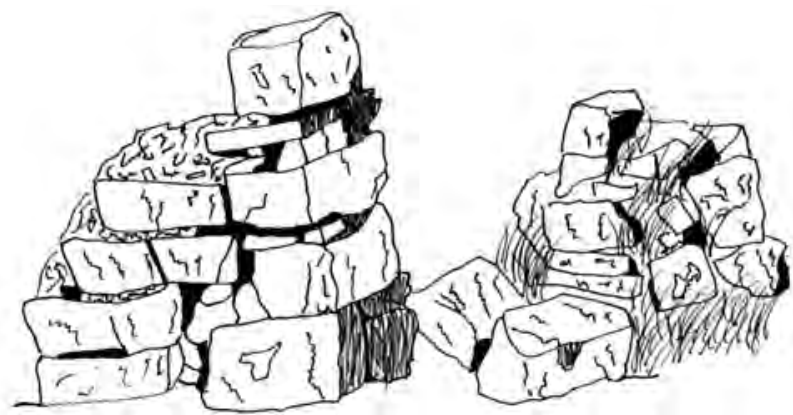

Figura 4. Detalle de la construcción del acceso a una estructura rectangular Huamaní, Huangáscar. 
encontramos una estructura que podría ser una "pileta" construida de un bloque de piedra, de base semicircular, con $1.20 \mathrm{~m}$ de profundidad. De la plataforma natural y con dirección al Este se halla una superficie casi plana y subiendo por dos escalones labrados en la piedra ingresamos a otro nivel, donde al costado de un bloque de piedra hallamos otra estructura semicircular, lugar en el que según un poblador nos contó "se depositaban poronguitos llenos de agua como ofrenda para que Huamaníles concedaagua".

\section{Quencho}

El sitio arqueológico de Quencho se ubica en la margen izquierda del río Huangáscar. Desde el sitio de Pucahuasi hacia el norte se observa una elevación que a simple vista podría tratarse de un puesto de vigilancia debido a su ubicación estratégica y de difícil acceso, pues ocupa la cima del cerro de fuerte pendiente (a excepción del lado sureste donde hay una planicie larga que continua hasta el sitio de Pucahuasi).

Su entrada es por el lado sur con una escalera que ha sido trabajada en la misma piedra y en la que se observan 9 escalones. Al subir por aquí llegamos a un nivel superior donde hay una muralla que mide $8 \mathrm{~m}$ aproximadamente de largo, el cual da paso a un patio con algunas construcciones de forma circular.

Las estructuras han sido construidas a base de piedras sin labrar o poco labradas, aparejadas sin orden de hiladas ni tamaño, unidas o no con argamasa.

Hacia el lado sur, a pesar de ser bastante empinado, se ubican recintos circulares, cada uno con su depósito.

\section{Pucahuasi}

El sitio arqueológico se ubica en la margen izquierda del río Huangáscar, en la cima del cerro Pucahuasi, a 3,595 m.s.n.m.

Los recintos arquitectónicos se emplazan sobre la parte alta del cerro, que tiene un relieve topográfico irregular; por el lado sur del sitio se presenta una fuerte pendiente y áreas rocosas, a excepción del lado noreste donde se presenta una planicie larga y estrecha.

Pucahuasi presenta murallas naturales constituidas por zonas rocosas de fuerte pendiente ubicadas en los lugares desprovistos de obstáculos naturales. La arquitectura se encuentra aglutinada, sin espacios vacíos y los recintos están protegidos por las murallas.

Encontramos dos accesos principales: uno ubicado en el lado sureste mirando hacia el sitio arqueológico de Huamani, y el otro al noroeste, conectado con un camino asociado a una zona de andenes.

Al ingresar al sitio por el acceso sureste encontramos un recinto rectangular que conduce de forma directa al sector principal. El camino que conduce al acceso sureste es muy intrincado a diferencia del acceso noroeste que nos lleva directamente a las estructuras circulares que predominan en este lugar.

En el interior del sitio arqueológico encontramos muy pocos recintos construidos sobre plataformas artificiales. Por el lado oeste nos encontramos con varios muros de contención muy cercanos entre sí. Predominan los recintos circulares y semicirculares agrupados irregularmente.

\section{División del espacio}

En Pucahuasi se distinguió 3 sectores: (Figura 5).

\section{Sector I}

Ubicado en la parte central y más alta del sitio de Pucahuasi, con orientación al Sur. Es el sector principal del asentamiento, compuesto por una plaza que mide $35 \mathrm{~m}$ de largo y de forma rectangular. Desde allí se domina el lado sur y sureste, por donde se corta debido a la presencia de una pendiente abrupta que impide el acceso por esta sección. Dicha ubicación domina el área de los sitios de Huamani, Viñaccancha y todos los pisos más altos de la región.

Al este de la plaza se sitúa una estructura circular de $7 \mathrm{~m}$ de diámetro aproximadamente, 


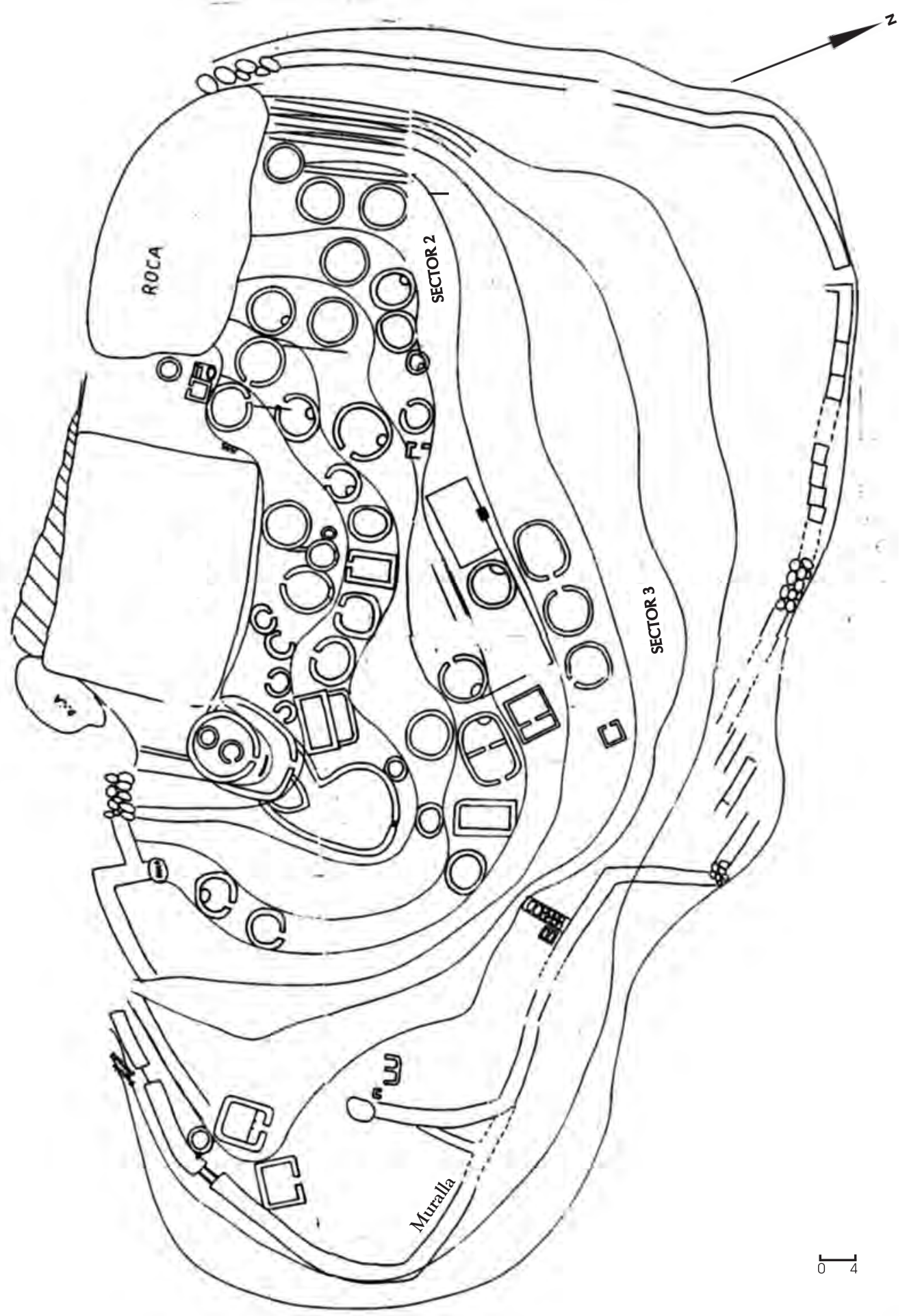

Figura 5. Sectores del sitio de Pucahuasi, Huangáscar. 
con acceso al noreste y en cuyo interior se encuentran dos pequeñas estructuras circulares. La primera cercana al muro suroeste, mide 2.20 $\mathrm{m}$ de diámetro, con ancho de muro de $40 \mathrm{~cm}$ y con acceso al este. La segunda estructura mide 1.90 m de diámetro, y esta separada de la anterior por $60 \mathrm{~cm}$. No presenta acceso.

Al noreste de esta estructura se encuentra un pequeño escalón que da lugar a otra estructura circular que circunda a aquélla pero en un nivel más bajo, con acceso orientado al noreste; esta estructura da paso a un patio semicircular cuya entrada estáal noreste y presenta dos escalones.

$\mathrm{Al}$ oeste de la plaza se ubica una plataforma que conduce a una pequeña estructura cuadran- gular semisubterránea de 2 por $2 \mathrm{~m}$, en donde se encuentra una piedra labrada de $1.50 \mathrm{~m}$ de largo. El muro sur presenta una hornacina de $39 \mathrm{~cm}$ de ancho. En una de las esquinas encontramos restos óseos y al costado aún se conserva parte del techo constituido por grandes lajas de piedra. $\mathrm{Al}$ sur ubicamos una estructura circular de $2 \mathrm{~m}$ de diámetro (Figura 6).

Por el lado norte de la plaza se hallan estructuras circulares y otras semicirculares, con $5 \mathrm{~m}$ de diámetro. Una de ellas presenta escalinatas. Cerca de ésta ubicamos estructuras circulares más pequeñas de 2.30 a $1 \mathrm{~m}$ de diámetro. Los depósitos subterráneos, adosados y debajo de los muros fueron ubicados en sólo dos estructuras.

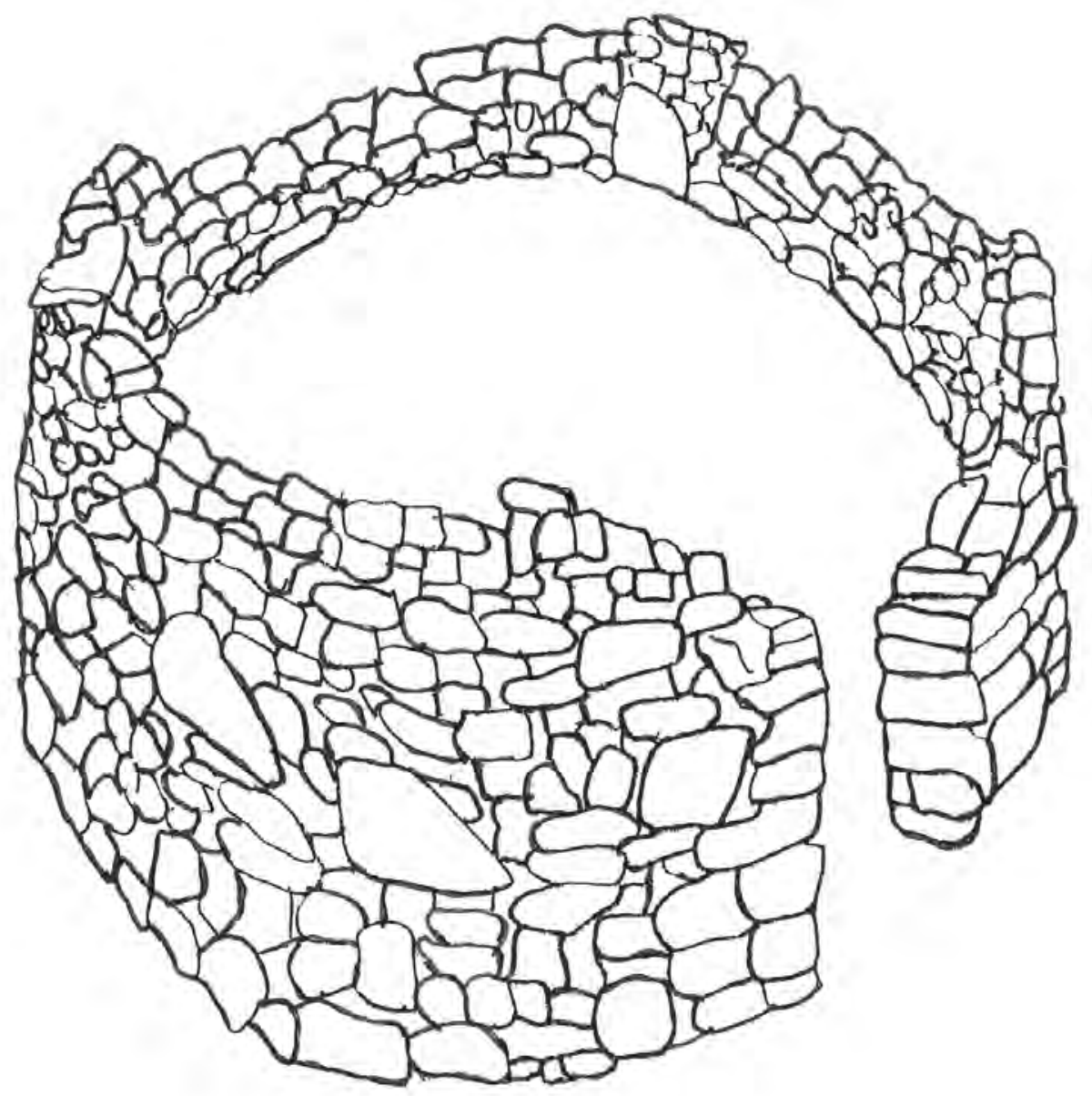

Figura 6. Estructura de forma circular. Pucahuasi, Huangáscar. 


\begin{abstract}
Sector II
Ubicado al noreste del sector principal, está conformado por estructuras circulares de $5 \mathrm{~m}$ de diámetro aproximadamente. Estas se asocian a plataformas artificiales, las cuales están reforzadas por muros de contención. (Fotografía 5). Se presentan sólo recintos circulares no alineados, mostrando irregularidad en la distribución. Los accesos observados no siguen una misma orientación y en una de las estructuras se halló un depósito semisubterráneo pegado al muro. Por el lado oeste de este sector se halló más muros de contención no asociados a estructuras. Desde este sector comienza la muralla oeste; además se tiene una visión del pueblo de Chocos.
\end{abstract}

\section{Sector III}

Se ubica en la parte norte de Pucahuasi. Desde esta zona se domina el área agrícola conformada por andenes que están orientados en dirección al pueblo de Huangáscar.

Los recintos se encuentran más ordenados y espaciados, con plantas de forma circular, semicircular y rectangular sobre plataformas rectangulares. También encontramos corredores entre ellas. Algunas estructuras rectangulares y semicirculares se encuentran divididas al interior en dos espacios por muros que presentan accesos. Los diámetros de los recintos circulares varían entre 5 y $6 \mathrm{~m}$. Una plataforma rectangular contiene dos estructuras circulares con depósitos en su interior; también se encuentra otro espacio separado con una plataforma rectangu- lar más pequeña de 10 por $6 \mathrm{~m}$, con muros de 1 $m$ de alto y con escalinatas de 5 peldaños construidas con piedra y argamasa. El espesor de los muros varía de 40 a $60 \mathrm{~cm}$. Ubicamos al noreste un recinto cuadrangular y pequeño de $2 \mathrm{~m}$.

\section{Cementerio}

Es otro de los sectores ubicados al norte y fuera de las murallas de Pucahuasi: se hallaron 6 recintos circulares cubiertos con grandes lajas de piedra de $2 \mathrm{~m}$ de diámetro aproximadamente y 2 m de profundidad. Desde de los accesos se distinguen restos óseos; los techos son del tipo falsa bóveda (Figura 7).

Están construidos con piedras canteadas unidas con argamasa de barro. Se emplazan los recintos funerarios sobre un terreno plano de tierra apisonada. No se halló cerámica en este sitio.

\section{Cerámica recolectada}

Se analizó la cerámica de superficie para definir la cronología ocupacional de los sitios: Pucahuasi, Huamani, Viñaccancha, Quencho y Huantanga. No se halló ningún fragmento en el sector del cementerio de Pucahuasi, lo que nos pareció extraño. 


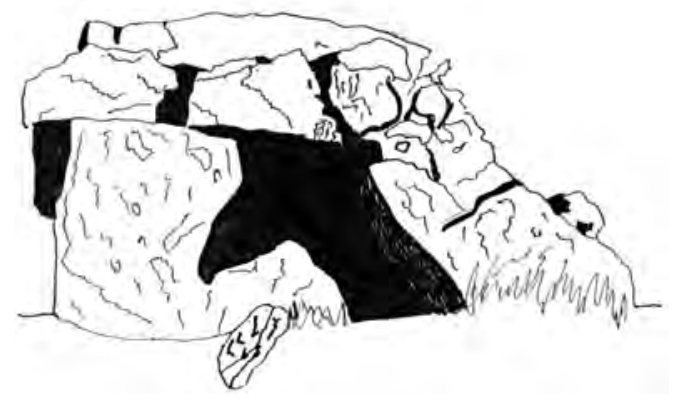

Figura 7. Detalle de la construcción del cementerio, falsa bóveda Pucahuasi.

Describiremos a grandes rasgos los caracteres diagnósticos de la cerámica recolectada de los 5 sitios.

\section{Material cerámico de Pucahuasi}

Según la clasificación por pasta, encontramos dos grupos:

\section{Grupo A}

Composición de la pasta: Es de textura muy tosca, los temperantes se caracterizan por presentar abundante piedra molida, calcita, en menor proporción la mica y pirita. El color de la pasta es marrón.

Manufactura: Modelada, de muy burda factura, el espesor de las paredes es de 5 a $12 \mathrm{~mm}$. El tratamiento de la superficie interior y exterior es el alisado mayormente tosco con estrías. El acabadode la superficie es descuidado.

Cocción: Casi la totalidad de los fragmentos observados presentan la parte media de color negro por defectos durante la cocción. La cocción ha sido en atmósfera oxidante.

Morfología: Las formas más comunes son ollas grandes y cántaros de bordes evertidos con labios rectos y convexos; hay muy pocos de bordes directos y semicurvados. El diámetro varía entre 15 y $40 \mathrm{~cm}$ (Figura 6). Las asas halladas pertenecen al tipo cintada lateral y vertical (Figura 7).

Decoración: Solo se encontró decoración con aplicaciones alrededor del cuello, éstas eran en forma de botones y tronco-cónica.

\section{Grupo B}

Composición de la pasta: De textura media. Contiene como temperantes calcita, mica y pirita en mayor proporción. El color de la pasta es anaranjado oscuro y marrón.

Manufactura: Cerámica modelada. Presenta huellas del alisado tosco. La superficie es regularmente uniforme. Las paredes de los fragmentos varían de 4 a $6 \mathrm{~mm}$.

Cocción: Se identifica la cocción en atmósfera oxidante. La consistencia es compacta.

Morfología: Las formas más comunes son los cuencos con diámetros que van de los 18 a 28 $\mathrm{cm}$, de bordes evertidos, con labios rectos y en algunos casos engrosados (Figura 8).

Decoración: Solo un fragmento presenta la decoración pintada de color marrón de líneas horizontales y verticales que se cruzan, que van al interior de la cerámica, comenzando desde el borde.

\section{Material cerámico de Viñaccancha}

Describimos a continuación la cerámica clasificada en dos grupos.

\section{Grupo A}

La pasta es de textura gruesa, los temperantes son calcita, arenisca, piedra molida, cuarzo y pirita, el color de la pasta es marrón claro a oscuro. De manufactura modelada. El espesor de las paredes es de 5 a $10 \mathrm{~mm}$. El tratamiento de la superficie es el alisado. La cocción fue en atmósfera oxidante y en un bajo porcentaje en atmósfera reductora. Las formas que predominan son los cántaros, ollas y cuencos de bordes rectos y evertidos. Los diámetros van de 14 a $40 \mathrm{~cm}$. Las asas son del tipo cintada lateral (Figura 9).

La decoración es el pintado en colores blanco, marrón oscuro y marrón rojizo. También se presentan aplicaciones a manera de botones alrededor del cuello e incisiones lineales en las asas.

\section{Grupo B}

La pasta es de textura media a fina, los temperantes son calcita y pirita. El color de la pasta 
18
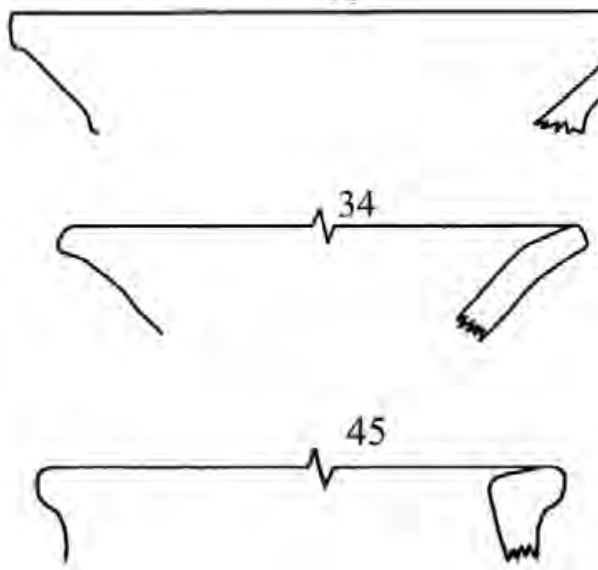

Figura 6.
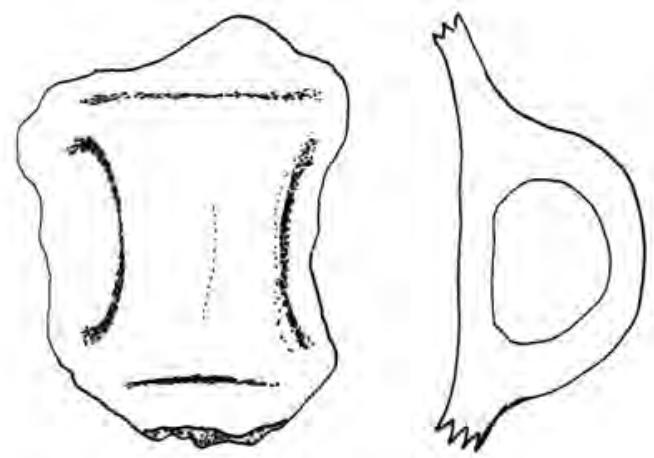

Figura 7.

es marrón y negro. La cerámica es modelada, con 4 a $6 \mathrm{~mm}$ de espesor de las paredes. El tratamiento de la superficie es el alisado fino que deja una superficie regular y el pulido. La cocción es en atmósfera oxidante y reductora. Las formas presentes son los cántaros, platos y cuencos de bordes evertidos y labios redondeados y rectos. Los diámetros varían entre 7 y $20 \mathrm{~cm}$ (Figura 10). La decoración es el pintado en colores blanco y negro sobre rojo. También se distinguen incisiones de líneas curvas alrededor del borde que se asemejan a las huellas de la uña.

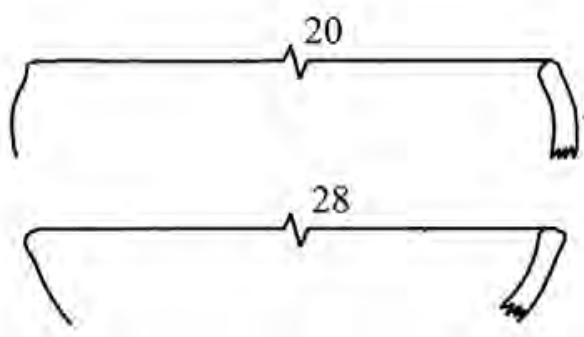

Figura 8.

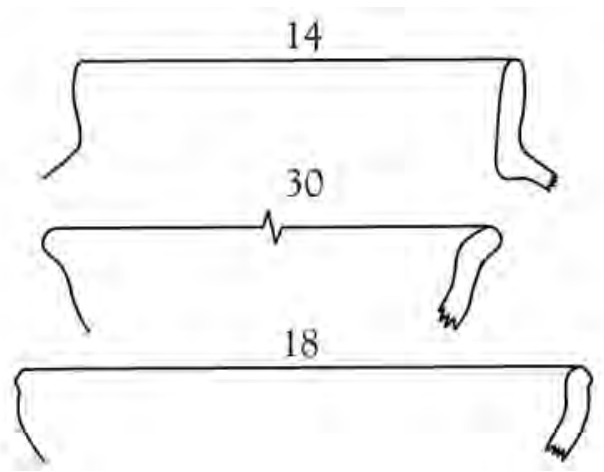

Figura 9.

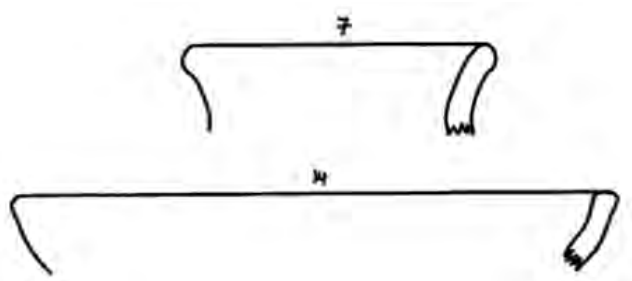

Figura 10.

\section{Material cerámico de Huantanga}

En el sitio de Huantanga se recogió sólo 9 fragmentos, el color de la pasta es marrón y de textura gruesa. Los temperantes más comunes son la calcita, cuarzo, piedra molida, pirita y mica. La cerámica fue modelada y cocida en atmósfera oxidante. El tratamiento de la superficie fue el alisado. El espesor de las paredes va de 6 a $8 \mathrm{~mm}$. Se hallaron dos bordes rectos y evertidos de cuencos con labios redondeados. Los diámetros van de los 14 a $16 \mathrm{~cm}$. La decoración utilizada es la pintura en color marrón. En los cuencos 
o platos la decoración es en el interior. Un solo fragmento con engobe presenta 7 agujeros de 5 mm de diámetro. Las asas encontradas son del tipo cintada.

\section{Material cerámico de Quencho}

Se recogieron 21 fragmentos. La cerámica se caracteriza por ser de textura gruesa; la pasta varía de un marrón claro a un marrón oscuro; predominan como temperantes la piedra molida, cuarzo, pirita y calcita. La cerámica fue modelada y cocida en atmósfera oxidante. El tratamiento de la superficie interna y externa fue el alisado tosco con marcadas estrías, mayormente al interior de la vasija. El espesor de las paredes varía de 4 a $8 \mathrm{~mm}$. Los bordes son evertidos y de labios redondeados y adelgazados, con diámetros de $20 \mathrm{~cm}$. También se presentan asas cintadas. No se presenta decoración.

\section{Material cerámico de Huamani}

En este sitio se recogió un total de 61 fragmentos de los cuales un $57 \%$ es material diagnóstico. Todos pertenecen al Intermedio Tardío. Los clasificamos en dos grupos:

\section{Grupo A}

El color de la pasta varía de marrón claro a marrón oscuro. Los temperantes comunes son la piedra molida, pirita y mica. La textura varía de media a gruesa. Cerámica de manufactura modelada. El tratamiento de la superficie es el alisado tosco. El grosor de las paredes varía de los 5 a 10 $\mathrm{mm}$. La cocción de las vasijas fue en atmósfera oxidante, presentando la parte media color negro. Las formas más comunes son los cántaros, ollas y cuencos. Los bordes obtenidos son el directo, invertido y evertido, reforzados externa e internamente de labios redondeados y rectos. Los diámetros de los bordes varían de los 14 a $38 \mathrm{~cm}$. Nopresentandecoración.

\section{Grupo B}

La pasta es de textura media. Contiene como temperantes el cuarzo, mica y pirita. El color de la pasta es anaranjado y marrón oscuro. La manufactura es modelada. La superficie interna y externa fue alisada. Las paredes de los fragmentos varían de 4 a $8 \mathrm{~mm}$. La cocción fue en atmósfera oxidante. Se presentan las formas de cuencos en mayor porcentaje con diámetros de $15 \mathrm{a} 23 \mathrm{~cm}$, de bordes invertidos, con labios redondeados y rectos. La decoración es pintada en color marrón y naranja en el exterior de lavasija.

\section{Discusión}

En el Período Intermedio Tardío el patrón que más se encuentra difundido en la sierra central de Perú es la ocupación de las zonas altas. Los asentamientos se encuentran fortificados por murallas naturales o artificiales debido a los conflictos surgidos entre las etnias por problemas de territorialidad. Esto explica el por qué, durante este período, los sitios arqueológicos se ubican en lugares estratégicos y defensivos, generalmente en las partes más altas de los cerros desde donde podían tener una mayor visibilidad del territorio; además se evitaba la ocupación de las áreas de cultivo.

Al ser ocupada la cima de los cerros, se lograba tener acceso a las áreas de pastos de la puna, importante para la alimentación de camélidos, los cuales les proveían de alimentos, textiles y transporte. Esta situación se presenta en la sierra de Lima, específicamente en la cuenca alta del río Cañete.

La ubicación estratégica del sitio de Pucahuasi no sólo respondía a fines defensivos, sino también a fines económicos. Debe de haber tenido Pucahuasi un desarrollo económico importante basado en la agricultura, apreciándose aún en la actualidad una impresionante cantidad de andenes, con sistemas de irrigación por canales que cubren un vasto sector de tierras fértiles. Siendo evidente la capacidad organizativa de trabajo empleado para la construcción de este sitio arqueológico.

Pero hoy en día el desarrollo económico alcanzado en el pasado ha desaparecido, los andenes se encuentran en un completo estado de abandono. 
En cuanto a la ocupación del terreno creemos que el sitio de Pucahuasi solo tuvo ocupación durante el Intermedio Tardío, y esto debido a que su arquitectura no muestra grandes rasgos de modificación o reutilización. Además, los fragmentos de cerámica presentes en la superficie solo corresponderían a este período, no encontramos en ningún sitio visitado fragmentos de cerámica inca. Parece ser que el sitio de Pucahuasi fue abandonado durante el período del Horizonte Tardío, quizás debido a su inaccesibilidad o por la falta de agua producida por los cambios climáticos que ocasionaron un descenso del nivel de las aguas de las lagunas ubicadas en las partes altas.

De acuerdo con nuestros datos podemos decir que, frente a la variedad arquitectónica de Pucahuasi, su tamaño y su posición estratégica, este sitio conformó un centro habitado por una etnia que pertenecería al grupo yauyos. Fue un centro administrativo con caracteres públicos que no presenta el patrón de asentamiento de los yauyos, pero sí se asemeja al patrón de asentamiento de los sitios ubicados en la margen izquierda de la cuenca alta del río Cañete, como es el caso del sitio de Sinchimarca (E. Enriquez, comunicación personal).

Partiendo de la premisa de que durante la expansión de los yauyos el poder político se concentró en Huarochirí, los grupos que se encontraban en la margen izquierda quedaron relegados y mantuvieron relaciones más estrechas con sus vecinos, los astos (pertenecientes a la etnia Anqara) y los chocorbos (ubicados en el departamentodeHuancavelica).

En lo arquitectónico, el sitio de Pucahuasi comparte la tradición arquitectónica de las formas circulares registradas en el territorio de los astos y los huancas. Esta área de investigación está muy relacionada con el departamento de Huancavelica y con el valle del Mantaro, debido a que anteriormente existían caminos de herradura que unían a los pueblos de estas regiones.
Pucahuasi tuvo una función de centro administrativo y de defensa dentro de su característica de poblado, pero no solamente cumplió estas funciones, sino también funciones públicas; fue un centro fortificado en donde se desarrollaron diferentes actividades.

Debemos destacar que Pucahuasi debió compartir alguna relación con los sitios de Quencho y Huamaní. Con el sitio de Quencho lo une un camino. El sitio de Quencho es pequeño y desde él se domina parte del área agrícola de esta zona.

Con el sitio de Huamaní debe de tener una relación mucho más estrecha porque éste no tiene un dominio de áreas agrícolas lo que sí se presenta en Pucahuasi, por lo que planteamos que Huamaní habría cumplido una función religiosa y Pucahuasi una función administrativa del área agrícola.

Esta complementariedad se da en algunos sitios de Tarma y Chinchaycocha, donde muchos asentamientos comprenden dos subdivisiones espacialmente distintas en algunos casos; los dos asentamientos distintos en tamañoy complejidad se encuentran muy juntos a lo largo de una sola cresta del cerro o sobre un par de colinas que se encuentran muy cerca una de la otra, (Parsons y Hastong 1978).

En lo referente al sistema de almacenes, parece haber sido manejado a nivel familiar por las fosas de almacenaje subterráneo, halladas al interior de las estructuras, similares a las descubiertas por la Lavalleé ( Lavalleé, 1973: 103) en los sitios de Anqara.

Para el sitio de Viñaccancha planteamos que debe investigarse más, porque parece ser que su economía se basaba en la agricultura en andenes y la ganadería de camélidos (hay estructuras circulares que serían corrales).

Debemos aclarar que hace falta investigar otros sitios de la margen izquierda del río Cañete, pero esto implicaría más tiempo en el campo y una mayor financiación para poder realizarlo. 


\section{Bibliografía}

Anónimo

1919 "Idolatrías de los Indios, Huachos y Yauyos, Misión de las provincias de los Huachos y Yauyos, 1613”. Histórica.

Dávila Briceño

1964 "Descripción y relación de la provincia de los Yauyos toda, Aman Yauyos y Hurín Yauyos hecha por Diego Dávila Corregidor de Guarochirí", en Relaciones geográficas de Indias. Jimenes de la Espada, Madrid.

Fonseca Martel, César

1983 "El control comunal del agua en la cuenca del río Cañete”. Allpanchis NŸ22, año XII, vol. XIX, Cuzco.

1988 Comunidad y producción en la Agricultura Andina. Enrique Mayer Compilador. Lima: Fonciencias.

Ginocchio L., María

1994 "Rasgos Gramaticales y Léxico del Quechua de Huangáscar contrastado con otros dialectos”. Tesis para optar el título de Licenciada en Lingüística, Facultad de Letras y Ciencias Humanas, Lima: UNMSM.

Instituto Nacional de Recursos Naturales, Inrena

1996 Evaluación Técnica para formular proyectos de riego en la provincia de Yauyos. Lima, 12 p. Anexos.

Lavalleé, Danielle

1973 "Estructura y organización del hábitat en los Andes Centrales durante el Período intermedio Tardío". Revista del Museo Nacional. Lima, Tomo XXXIX, pag. 91116.

Lavalleé, Danielle y Michele, Julien

1983 Asto: Curacazgo prehispánico de los Andes Centrales. Lima: IEP.

Marcus, J. y Silva, J.

1988 "Cultivos de coca en el valle del río Chillón y su contexto ecológico, arqueológico y etnohistórico", en Memoirs of the Museom of Anthropology. University of Michigan. N $\ddot{2}$ A.
Matos Mar, José

1950 "Marco geográfico del área cultural Kauke en el Perú". Revista de Letras, NŸ 44, Lima: UNMSM.

Matos M. Ramiro

1960 "Informe sobre trabajos arqueológicos en Castrovirreyna, Huancavelica", Mejía Baca (ed.). Antiguo Perú espacio y tiempo, Lima.

Morales Ch. Daniel

1993 Compendio Histórico del Perú. Tomo I. Lima: Ed. Milla Batres.

Oner

1989 "Inventario y Evaluación de los Recursos Naturales de la Microrregión de Yauyos. Departamento de Lima”. Lima: CORLIMA 2 tomos, vol I; Informe, vol II Anexos y mapas.

Parsons, Jefrey y Ramiro Matos

1978 "Asentamiento pre-hispánicos en el Mantaro, Perú informe preliminar", en Ramiro Matos (ed.). III. Congreso Peruano: El hombre y la Cultura Andina. Actas y Trabajos, Tomo II, pág. 539-555.

Rostworowski, María

1978 Señoríos indígenas de Lima y Canta. Lima IEP.

1989 Costa Peruana Prehispánica. Lima: IEP.

1993 Ensayos de historia andina. elites, etnias, recursos. Lima: IEP, 460 p.

Ruiz, Enrique y Gori Echevarria

2002 "Algunos datos sobre la ocupación Inca en el valle de Cañete". Boletín del Museo de Arqueología y Antropología 5 (2): 50 55. Lima: UNMSM.

Taylor, Gerarld

1984 "Yauyos: un microcosmos dialectal quechua”. Revista Andina, Cuzco, Año 2 $\mathrm{NY}=$

1987 Ritos y tradiciones de huarochirí del Siglo XVII. Lima: IEP-IFEA.

Torero, Alfredo

1974 El quechua y la Historia Social Andina. Lima: Universidad Ricardo Palma. 